ANL/ET/CP- -89702

CONF $-9605167-1$

\title{
FRACTURE BEHAVIOR OF ADVANCED CERAMIC HOT-GAS FILTERS*
}

\author{
J. P. Singh, S. Majumdar, M. Sutaria, and W. Bielke \\ Energy Technology Division \\ Argonne National Laboratory \\ Argonne, Illinois 60439
}

May 1996

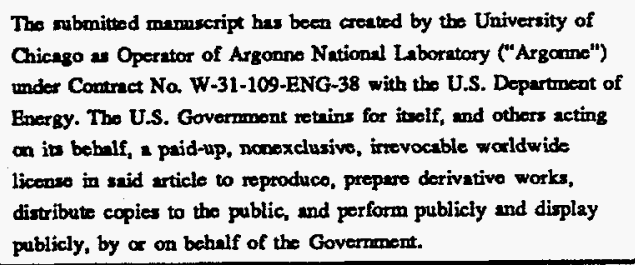

The submitted manuscript has been crested by the University of Chicago a Operator of Argonne National Laboratory ("Argame") under Contrect No. W-31-109-ENG-38 with the U.S. Department of Energy. The U.S. Govermmont retrins for iteclf, and others acting on its behalf, a paid-up, nonexelusive, irrevocable worldwide licenso in said article to reproduco, prepare derivative works, distribute copies to the public, and perform publicly and display publicly, by or on behalf of the Government.

\begin{abstract}
DISCLAIMER
This report was prepared as an account of work sponsored by an agency of the United States Government. Neither the United States Government nor any agency thereof, nor any of their employees, makes any warranty, express or implied, or assumes any legal liability or responsibility for the accuracy, completeness, or usefulness of any information, apparatus, product, or process disclosed, or represents that its use would not infringe privately owned rights. Reference herein to any specific commercial product, process, or service by trade name, trademark, manufacturer, or otherwise does not necessarily constitute or imply its endorsement, recommendation, or favoring by the United States Government or any agency thereof. The views and opinions of authors expressed herein do not necessarily state or reflect those of the United States Government or any agency thereof.
\end{abstract}

To be published in Proc. of 10th Annual Conference on Fossil Energy Materials, Knoxville, TN, May 14-16, 1996.

*Research sponsored by the Office of Fossil Energy, Advanced Research and Technology Development Materials Program [DOE/FE AA 151010 0, Work Breakdown Structure Element ANL-1A], U.S. Department of Energy, under Contract W-31-109-Eng-38. 


\title{
FRACTURE BEHAVIOR OF ADVANCED CERAMIC HOT-GAS FILTERS
}

\author{
J. P. Singh, S. Majumdar, M. Sutaria, and W. Bielke \\ Energy Technology Division \\ Argonne National Laboratory \\ Argonne, Illinois 60439
}

\begin{abstract}
We have evaluated the microstructural/mechanical, and thermal shock/fatigue behavior and have conducted stress analyses of hot-gas candle filters made by various manufacturers. These filters include both monolithic and composite ceramics. Mechanical-property measurement of the composite filters included diametral compression testing with O-ring specimens and burst testing of short filter segments using rubber plug. In general, strength values obtained by burst testing were lower than those obtained by O-ring compression testing.

During single-cycle thermal-shock tests, the composite filters showed little or no strength degradation when quenched from temperatures between 900 and $1000^{\circ} \mathrm{C}$. At higher quenching temperatures, slow strength degradation was observed. The monolithic SiC filters showed no strength degradation when quenched from temperatures of up to $\approx 700-900^{\circ} \mathrm{C}$, but displayed decreased strength at a relatively sharp rate when quenched from higher temperatures. On the other hand, a recrystallized monolithic SiC filter showed higher initial strength and retained this strength to higher quenching temperatures than did regular SiC filters. This may be related to the difference in strength of grain boundary phases in the two cases. In thermal cycles between room temperature and $800-1000^{\circ} \mathrm{C}$, both monolithic and composite filters show a small strength degradation up to three cycles, beyond which the strength remained unchanged.

Results of rubber-plug burst testing on composite filters were analyzed to determine the anisotropic elastic constants of the composite in the hoop direction. When these results are combined with the axial elastic constants determined from axial tensile tests, the composite can be analyzed for stress due to mechanical (e.g., internal pressure) or thermal loading (thermal shock during pulse cleaning). The stresses can be compared with the strength of the composite to predict filter performance.
\end{abstract}

\section{INTRODUCTION}

Hot-dirty gas exiting from a gasifier or an advanced combustor contains sufficient particulates to make the gas undesirable for direct utilization in gas turbines and heat engines. Today's hot-dirty gas cleanup systems, such as cyclones, can remove only the fraction 
containing the larger particulates. Smaller particulates can be removed only by cooling and filtering the gas. The resulting enthalpy loss causes a significant decrease in overall system efficiency. Thus, there is a critical need for cleaning hot-dirty gas with little or no cooling.

This project supports the development of candle ceramic/composite filters for cleanup of hot-dirty gases. Effort has been directed toward developing materials qualification technology needed to ensure satisfactory performance of filters in hot-dirty gas streams. To predict the long-term performance of such filters, it is important to understand and evaluate fracture behavior of these filters in service environments. Mechanical properties should be evaluated to establish baseline data. Thermal-shock resistance should be measured to predict filter performance in the service environment. ${ }^{1}$ Failure modes must be identified and failure mechanisms must be established.

\section{SPECIMENS FOR FRACTURE STUDY}

The filters examined in this study were obtained from $3 \mathrm{M}$ (Nextel/SiC composite filters), DuPont Lanxide (PRD-66 filters), Babcock \& Wilcox (oxide composites), Industrial Filter and Pump Mfg. Co. (IFPM) (regular monolithic SiC with high alumina binder and binderless recrystallized $\mathrm{SiC}$ filters) and Pall Corp. (monolithic $\mathrm{SiC}$ ). The $3 \mathrm{M}$ filters consist of layered composite structures; a tubular filter element is sandwiched between two Nextel/SiC composite tubes. Bonding between the Nextel/SiC composite tubes and the filter layer is achieved by the chemical vapor infiltration (CVI) of SiC. The inner and outer diameters of these filters are $\approx 5.08$ and $\approx 5.72 \mathrm{~cm}$, respectively. Filters were obtained in both as-fabricated and exposed (in the Tidd demonstration plant for $\approx 1100 \mathrm{~h}$ ) conditions. The PRD-66 is an alloxide ceramic consisting of layered microstructure of alumina, mullite, cordierite, and amorphous material; the inner and outer diameters are $\approx 4.52$ and $\approx 5.96 \mathrm{~cm}$, respectively. The Babcock \& Wilcox filter is made by a sol-gel technique and consists of an oxide composite with chopped and continuous Nextel fibers. The inner and outer diameters of the filters are $\approx 5.00$ and $\approx 5.96 \mathrm{~cm}$, respectively. Both of the monolithic $\mathrm{SiC}$ filters consist primarily of $\mathrm{SiC}$ grains; inner and outer diameters of the filters are $\approx 4.52$ and $\approx 5.96 \mathrm{~cm}$, respectively. 


\section{EVALUATION OF STRENGTH AND THERMAL-SHOCK \\ AND FATIGUE RESISTANCE}

Filter strength was evaluated by both diametral compression testing of O-ring specimens and by burst testing of short filter segments with rubber plugs.

\section{Q-Ring Compression Testing}

One-inch-wide O-ring specimens were machined from each of the filters and then loaded to failure in a diametral compression mode at a crosshead speed of $0.13 \mathrm{~cm} / \mathrm{min}$. Maximum stress develops at the inner diameter across the load points, which simulates the thermal-shock stresses developed during a pulse-cleaning cycle. The fracture stress $\sigma_{\mathrm{f}}$ is given by Eq. $1 .^{2}$

$$
\sigma_{f}=\frac{P K}{\pi b l}
$$

where $P$ is the fracture load, $\mathrm{K}$ is a function of the ratio of inner and outer diameters, ${ }^{2} \mathrm{~b}$ is the outer radius of the specimen, and $l$ is the length of the tube. Load displacement plots for the filter specimens in as-fabricated condition indicated a nonbrittle failure mode for all composites and brittle failure for the monolithic filters. A limited number of O-ring specimens machined from one of the composite filters exposed in the Tidd demonstration plant for $\approx 1100 \mathrm{~h}$ were tested in compression mode; strength was $7.72 \pm 1.13 \mathrm{MPa}$. The corresponding strength of the unexposed filter was $19.47 \pm 2.11 \mathrm{MPa}$. This represents a strength loss of $60 \%$ during filter exposure, which correlates very well with the strength loss of the reinforcing fibers and may be related to in-situ fiber damage during filter exposure. ${ }^{3}$

\section{Burst Testing}

Burst testing was performed on 1-in.-wide O-ring specimens machined from a Nextel/SiC composite filter in as-fabricated condition. As shown in Fig. 1, uniform radial loading was applied to the O-rings through a rubber plug (slightly smaller in diameter than O-ring) that was compressed between two aluminum plates. Figure 2 shows a typical loaddisplacement plot for a specimen in as-fabricated condition. 


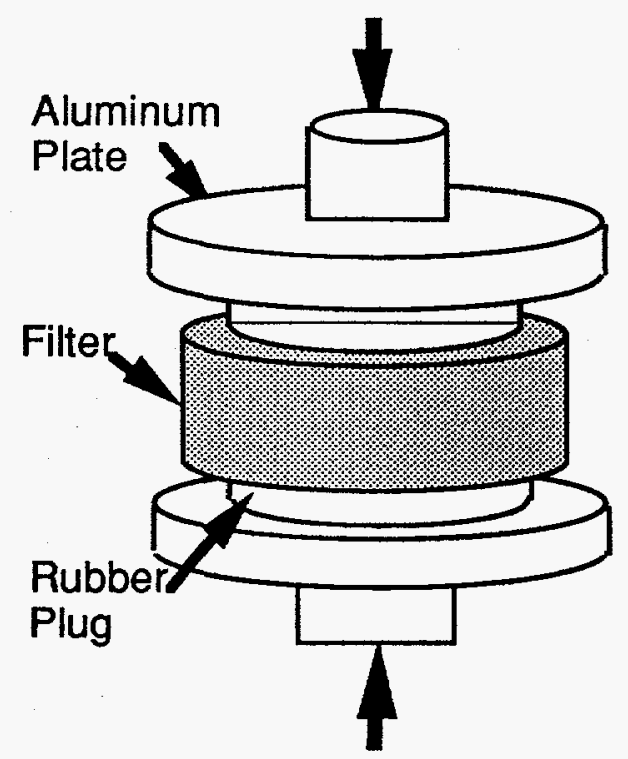

Fig. 1. Schematic diagram of burst test.

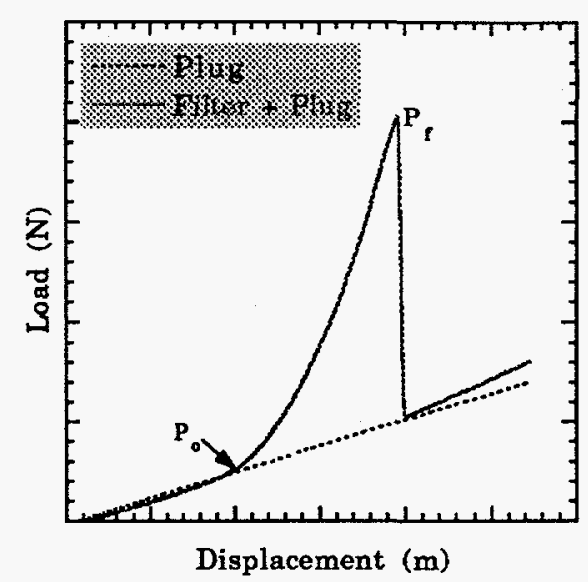

Fig. 2. Typical load-displacement plot for Nextel/SiC filter specimen.

The maximum hoop stress $\left(\sigma_{t}\right)$ occurs at the inner wall and is given by Eqs. 2 and 3:4,5

$$
\begin{aligned}
& \sigma_{t}=p^{L}\left(\frac{r_{o}^{2}+r_{i}^{2}}{r_{o}^{2}-r_{i}^{2}}\right) \\
& p^{L}=\frac{v}{(1-v)} \frac{\left(P_{f}-P_{o}\right)}{\pi r_{i}^{2}}
\end{aligned}
$$

where $\mathrm{p}^{\mathrm{L}}$ is is the radial pressure on the inner wall of the filter; $\mathrm{r}_{\mathrm{o}}$ and $\mathrm{r}_{\mathrm{i}}$ are the outer and inner radii of the filter, respectively; $P_{f}$ is the maximum applied load at fracture, $P_{o}$ is the load at which the rubber plug makes radial contact with the filter, and $v$ is the Poisson's ratio (value taken to be 0.5 ). The fracture load $P_{f}$ and contact load $P_{o}$ were obtained from the loaddisplacement plot. To date, a limited number of specimens have been evaluated by burst testing to compare the strength data with those obtained by $\mathrm{O}$-ring compression testing. For the Nextel/SiC composite filter specimens, burst strength was $6.4 \pm 0.22 \mathrm{MPa}$, a lower value than that obtained by O-ring tests. This difference is believed to be due to the larger specimen volume subjected to high stresses during burst testing than that in O-ring compression testing. 


\section{Thermal-Shock Testing}

Thermal-shock testing was performed on 1-in.-wide ring specimens machined from the filters. The ring specimens were insulated on the outer surface to simulate the heat transfer conditions in service. These specimens were heated to preselected temperatures $\left(25-1100^{\circ} \mathrm{C}\right)$ in an electric furnace. Subsequently, the specimens were quenched in silicone oil at room temperature $\left(\approx 25^{\circ} \mathrm{C}\right)$. Thermal-shock damage was estimated by measuring the strength of ring specimens by O-ring compression testing before and after thermal quenching.

The results of the thermal-shock experiments are given in Fig. 3, which shows the retained strength of specimens subjected to varying degrees of thermal quench $(\Delta \mathrm{T})$. Vertical bars represent the standard deviation when three or four specimens were tested. Other data points represent values for single specimens.

Results obtained so far indicate that the composite filters show little or no strength degradation when quenched from $\approx 900-1000^{\circ} \mathrm{C}$. At higher quenching temperatures, slow strength degradation was observed. The regular monolithic $\mathrm{SiC}$ filters showed no strength degradation when quenched from $\approx 700-900^{\circ} \mathrm{C}$. At higher temperatures, strength decreased at a relatively sharp rate. On the other hand, as seen in Fig. $3 b$, the recrystallized monolithic $\mathrm{SiC}$ filter specimens showed higher initial strength that was retained to higher quenching temperatures than in the regular $\mathrm{SiC}$ filter specimens. This may be related to differences in strengths of grain boundary phases in the two cases.

\section{Evaluation of Thermal-Fatigue Behavior}

Thermal-fatigue testing of both monolithic and composite filters was performed on 1-in.wide ring specimens machined from the filters. These specimens were thermally cycled between room temperature and preselected elevated temperatures of $800-1000^{\circ} \mathrm{C}$. The elevated temperatures were close to the critical quenching temperature observed in the single-cycle thermal quenching experiments. The ring specimens were insulated on their outer surfaces, as before, to simulate heat transfer conditions in service. Thermal-fatigue damage was estimated by measuring strength (in O-ring compression tests) of the specimens before and after thermal cycling. 


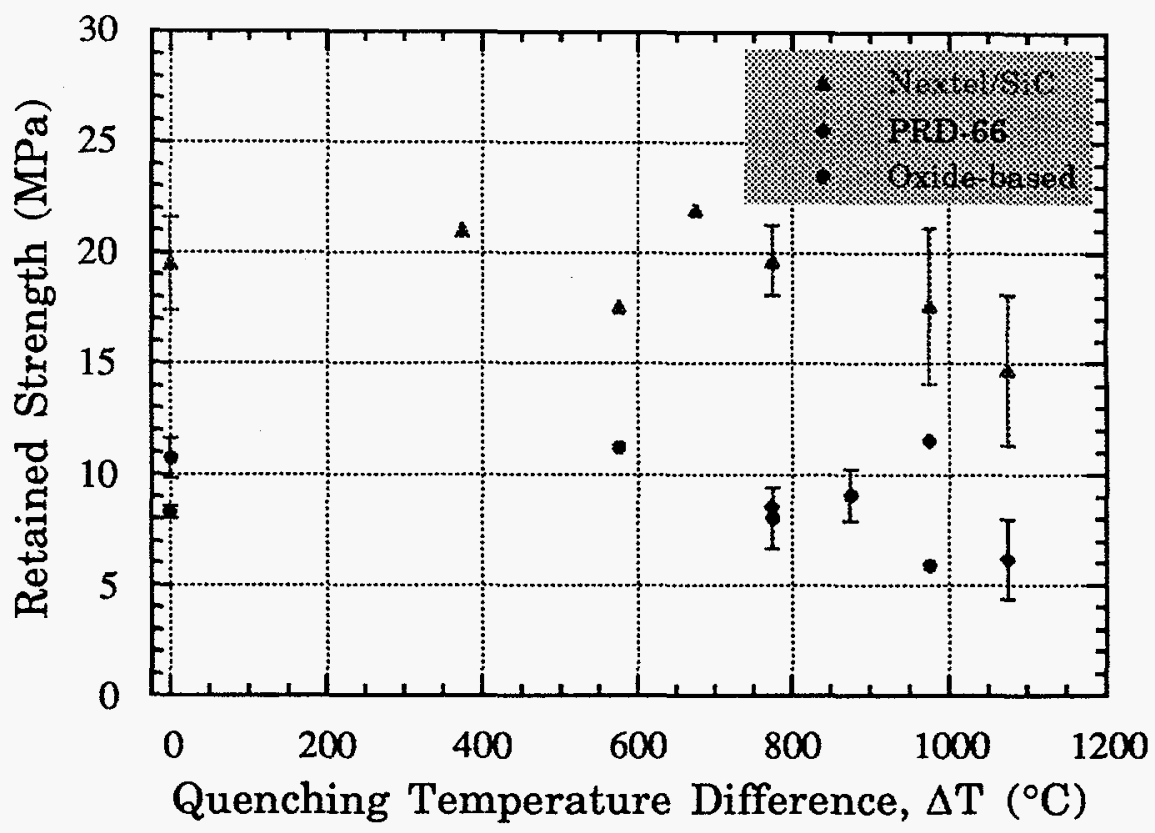

(a)

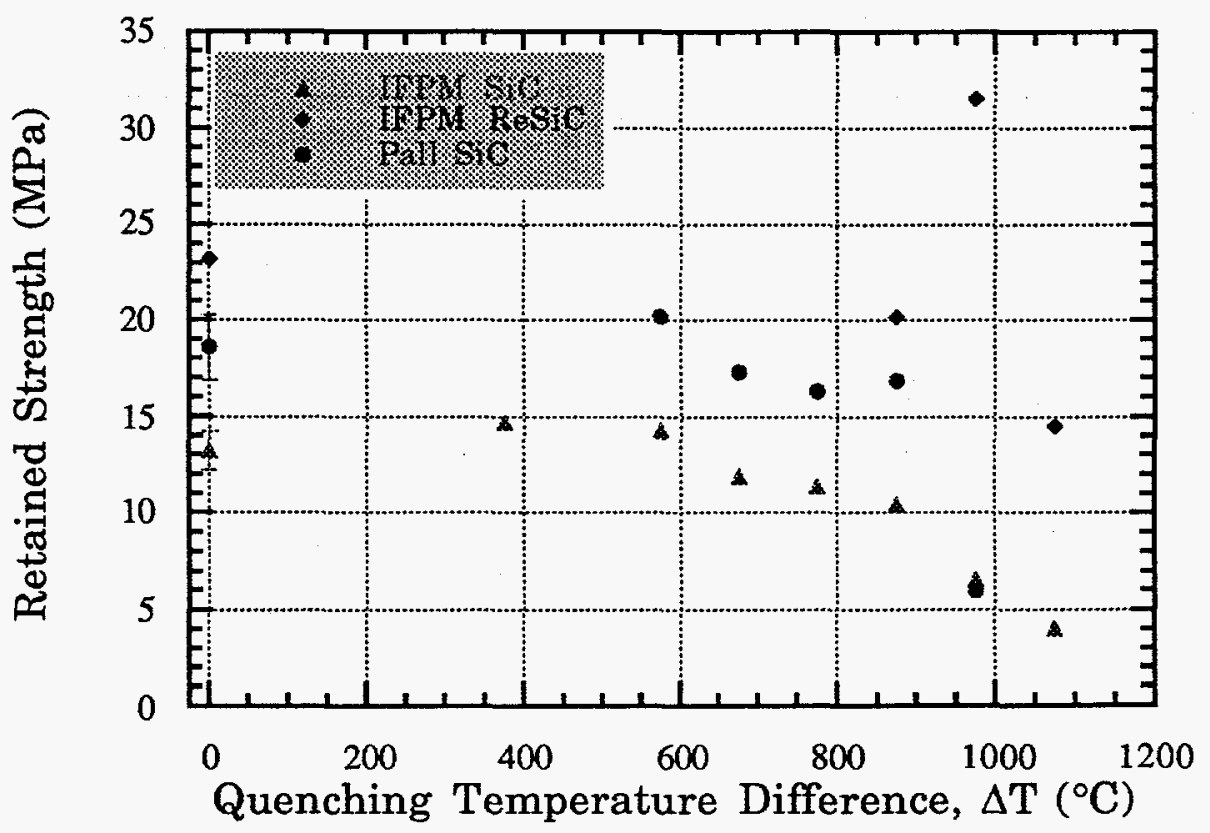

(b)

Fig. 3. Dependence of retained strength of ring specimens on quenching temperature difference $(\Delta \mathrm{T})$ : (a) $3 \mathrm{M} \mathrm{Nextel/SiC,} \mathrm{DuPont}$ Lanxide PRD-66, and Babcock \& Wilcox oxide-based composite filters; (b) IFPM monolithic SiC, IFPM monolithic recrystallized SiC, and Pall monolithic SiC filters. 
The results of the thermal-fatigue experiments are given in Fig. 4, which shows retained strength of filter specimens as a function of thermal cycles. Vertical bars represent the standard deviation when three or four specimens were tested. Other data points represent values for single specimens.

In thermal cycling between room temperature and $800-1000^{\circ} \mathrm{C}$, Nextel/SiC, PRD-66, and Babcock \& Wilcox composite filters show a small strength degradation (18-24\%) up to three cycles, beyond which strength remained unchanged. Similar behavior was observed for the monolithic filters that were thermally cycled between room temperature and $800^{\circ} \mathrm{C}$; initially, strength decreased by $15-28 \%$ up to about three cycles, beyond which the strength remained constant. On the other hand, in thermal cycling between room temperature and $900^{\circ} \mathrm{C}$, a large drop in strength was observed for the Pall monolithic filter, the reason for this behavior is currently under investigation to determine if the drop is just a scatter in data. Only one specimen was tested per condition because of limited filter. As expected, both the monolithic and the composite filters showed a slight decrease in strength when thermally cycled at higher temperatures. Microstructural evaluations are in progress to evaluate the failure modes and mechanisms; the results will be used for analytical modeling to predict filter performance in service.

\section{STRESS ANALYSIS OF O-RING BURST TESTS}

Recently, a series of burst tests were conducted on the composite filters by using an internal plug. This section summarizes an analysis of the results conducted in order to deduce the elastic stiffness properties of the composite materials.

\section{Geometry}

The geometry and loading of the composite O-ring burst tests are shown in Fig. 5. Radial pressure loading is achieved by an internal rubber plug that has an initial radial clearance at the inner diameter (ID) of the composite. The rubber plug is loaded axially in an Instron machine. Initially, the O-ring does not see any load, but after the radial gap between the O-ring and the composite is closed by lateral expansion of the plug (due to Poisson's ratio effect), the composite experiences a radial pressure loading. 


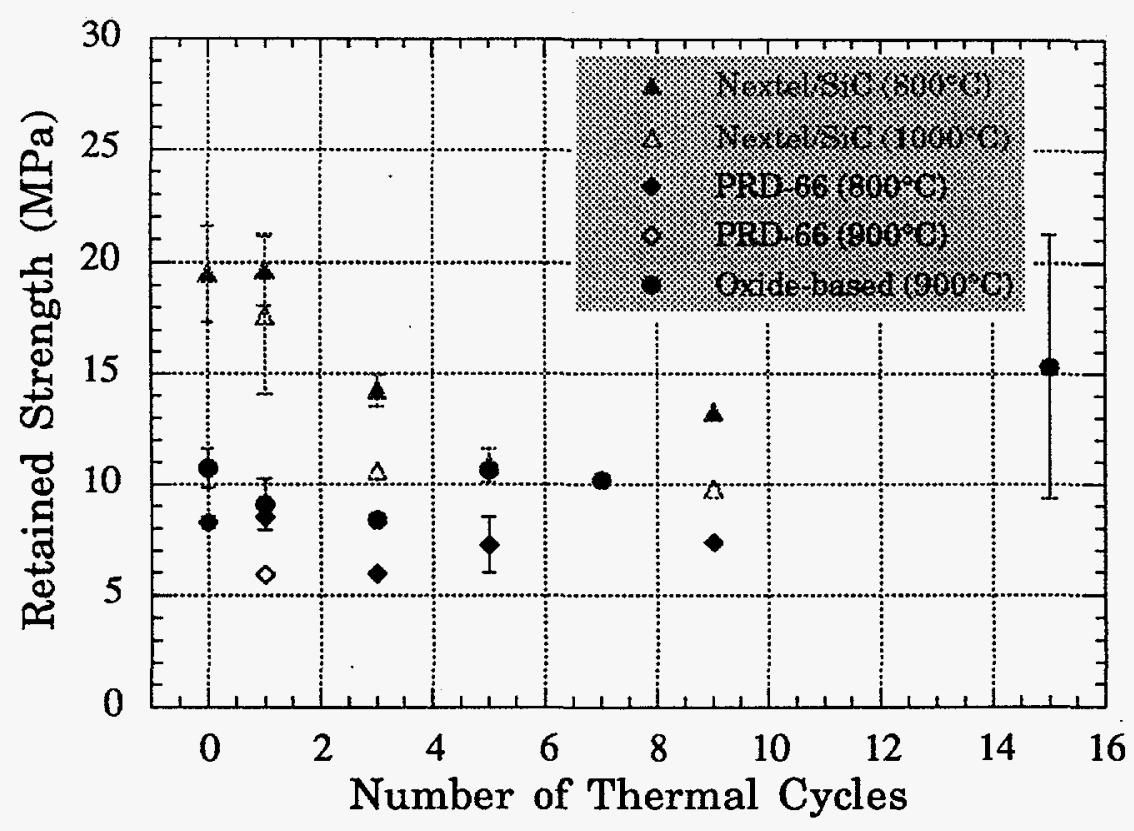

(a)

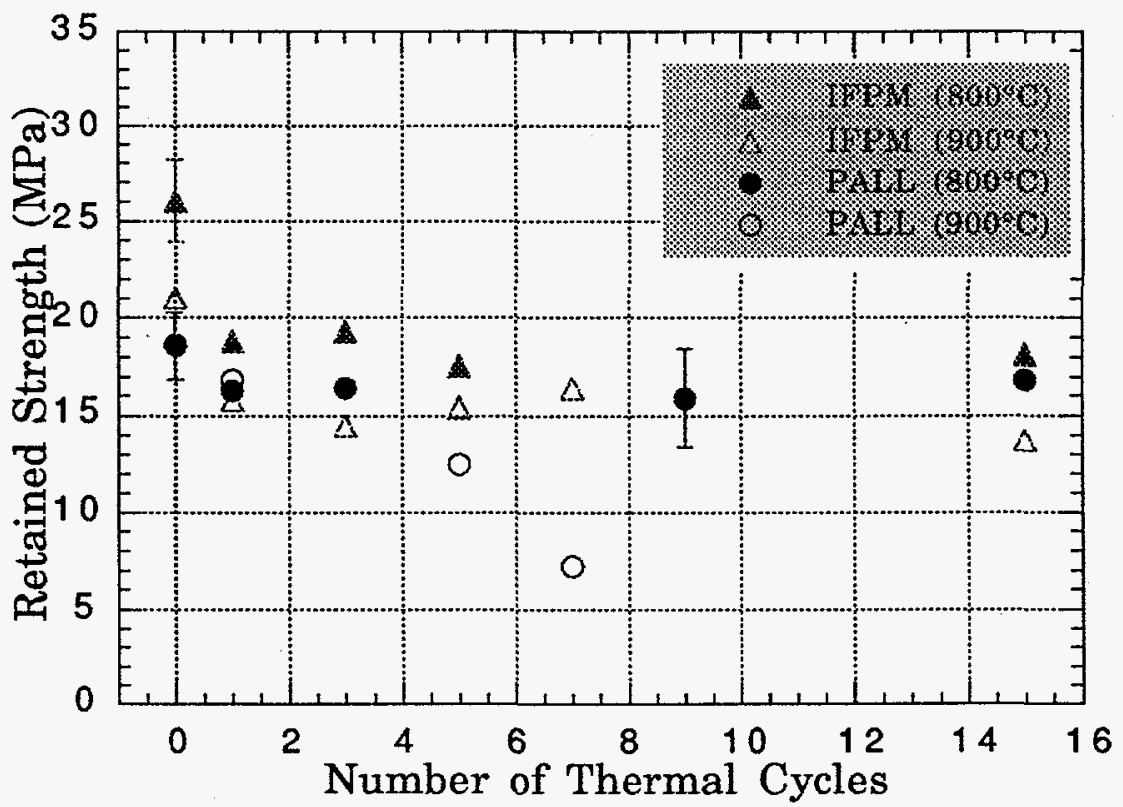

(b)

Fig. 4. Dependence of retained strength on number of thermal cycles: (a) 3M Nextel/SiC, DuPont Lanxide PRD-66, and Babcock \& Wilcox oxide-based composite filters; (b) IFPM monolithic SiC and Pall monolithic SiC filters. 

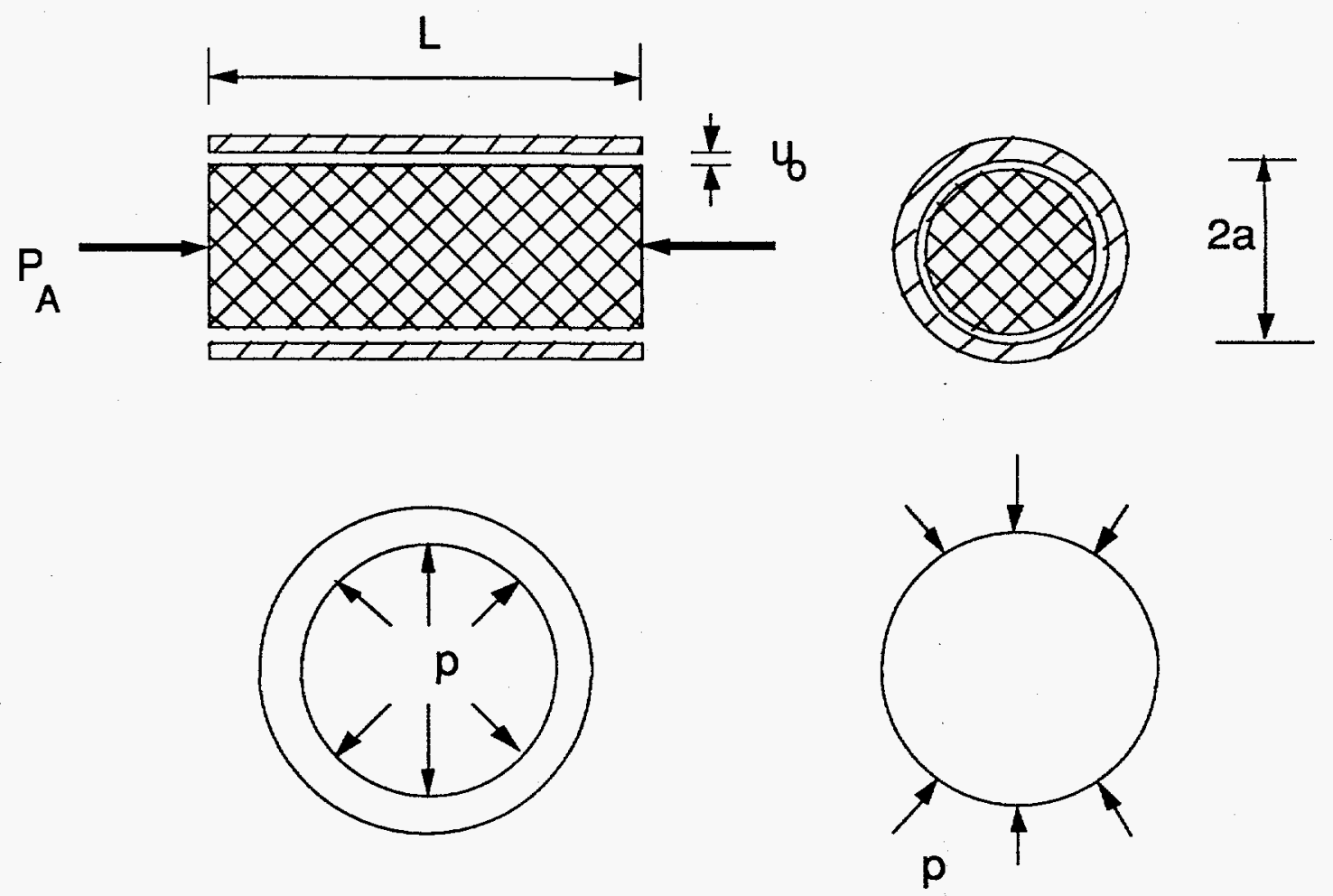

Fig. 5. Typical setup for O-ring burst test. Interfacial pressure $p=0$ until radial clearance $\mathrm{u}_{\mathrm{o}}$ is closed at axial pressure $\mathrm{p}_{\mathrm{Ao}}=\mathrm{P}_{\mathrm{Ad}} / \pi \mathrm{a}^{2}$.

\section{Analysis}

The in-plane stress resultants in the composite are related to the membrane strains by the stiffness coefficients $K_{x}, K_{y}$, and $K_{x y}$ as follows:

$$
\begin{aligned}
& N_{x}=K_{x} \varepsilon_{x}+K_{x y} \varepsilon_{y} \\
& N_{y}=K_{x y} \varepsilon_{x}+K_{y} \varepsilon_{y},
\end{aligned}
$$

where $\mathrm{N}$ and $\varepsilon$ are the stress resultants and strains, respectively; and subscripts $\mathrm{x}$ and $\mathrm{y}$ denote the axial and circumferential directions, respectively. We assume that the friction effects at the interface between the rubber plug and the composite O-ring are negligible, so that after contact, the composite experiences hoop stress only, i.e., $\mathrm{N}_{\mathrm{x}}=0$. In such a case, the above stress-strain relationship reduces to: 


$$
N_{y}=E_{y} \varepsilon_{y}=\left(K_{y}-\frac{K_{x y}^{2}}{K_{x}}\right) \varepsilon
$$

The radial clearance $u_{o}$ between the plug and the O-ring is closed at an axial pressure of $p_{A 0}$, where

$$
p_{A o}=E \varepsilon_{A o}=\frac{E \varepsilon_{o}}{v}
$$

where $\varepsilon_{\mathrm{o}}=u_{\mathrm{o}} / \mathrm{a}$, and $\mathrm{E}$ and $v$ are the Young's modulus and Poisson's ratio of the plug, respectively. Assuming the rubber plug to be incompressible $(v=0.5)$, the interfacial pressure $\mathrm{p}$ beyond the initial contact at an axial pressure $\mathrm{p}_{\mathrm{A}}$ is derived by:

$$
p=\frac{p_{A}-p_{A o}}{1+\frac{2 E a}{E_{y}}}=\left(1-\frac{E}{E_{1}}\right)\left(p_{A}-p_{A o}\right)
$$

where

$$
E_{1}=\frac{p_{A}-p_{A o}}{\varepsilon_{A}-\varepsilon_{A o}}=E\left(1+\frac{E_{y}}{2 E a}\right) .
$$

In Eqs. 6 and 7, $\mathrm{E}$ and $\mathrm{E}_{1}$ are the slopes of the axial stress-strain curve of the rubber plug before and after contact with the O-ring, respectively (Fig. 6).

An estimate for the stiffness of the O-ring can be obtained by solving Eq. 7 as

$$
E_{y}=2 a\left(E_{1}-E\right)
$$

Therefore, the hoop stress resultant corresponding to any axial pressure $\mathrm{p}_{\mathrm{A}}$ is given by

$$
\begin{array}{r}
N_{y}=p a=\frac{E_{y}}{2 E_{1}}\left(p_{A}-p_{A o}\right)=\left[1-\frac{E}{E_{1}}\right]\left(p_{A}-p_{A o}\right) a . \\
\underline{\text { O-Ring Burst Test }}
\end{array}
$$

\section{O-Ring Burst Test}

In an ideal O-ring burst test (Fig. 6) starting at $O$, the plug contacts the O-ring at a stress $\mathrm{p}_{\mathrm{Ao}}$ and strain $\varepsilon_{\mathrm{Ao}}$ (point $\mathrm{A}$ ), after which the load-displacement curve follows the steep curve 


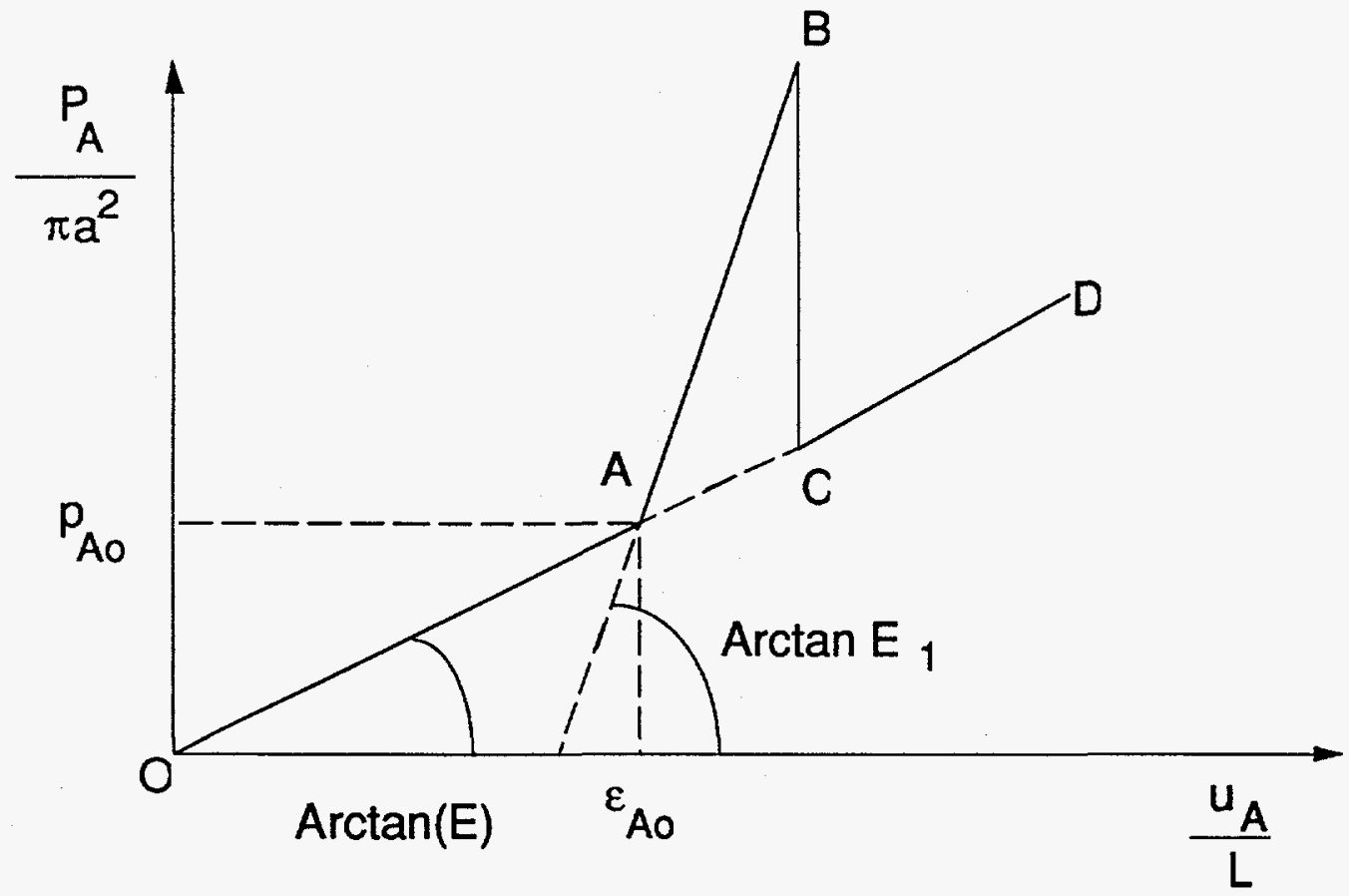

Fig. 6. Calculated idealized load-displacement curve.

$A B$ with slope $E_{1}$. After bursting of the ring at $B$, the load rapidly drops to $C$ and follows the original load-displacement curve for the plug along $\mathrm{CD}$. In reality, the discontinuous changes in slopes are replaced by gradual changes.

The measured values of the slopes, based on three tests are

$$
\begin{aligned}
& \mathrm{E}=(2.455 \pm 0.136) \mathrm{MPa} \\
& \mathrm{E}_{1}=(27.67 \pm 1.097) \mathrm{MPa}
\end{aligned}
$$

Using Eq. 8, we find that

$$
\mathrm{E}_{\mathrm{y}}=(1.2703 \pm 0.037) \times \mathrm{MN} / \mathrm{m} \text {. }
$$

The stiffness properties $\left(E_{x}, E_{y}\right.$, etc.) of the composite substrate tube (without filter layer) can be estimated from the measured values of the matrix and fiber properties. With known values of stiffness ( $E y$ ) for the composite filter (composite tube and filter layer) and composite substrate alone, elastic properties of the filter layer can be estimated. These 
properties will be used to analyze global stresses (thermal stresses, etc.) in composite filters to predict filter performance.

\section{ACKNOWLEDGMENTS}

The work was supported by the U.S. Department of Energy, Office of Fossil Energy, Advanced Research and Technology Materials Program [DOE/FE AA 151010 0, Work Breakdown Structure Element ANL-1A], under Contract W-31-109-Eng-38. The authors thank D. J. Pysher, B. L. Weaver, and R. G. Smith of the 3M Company, J. A. Chambers of DuPont Lanxide Composites, Inc., P. Eggerstedt and J. Zievers of the Industrial Filter \& Pump Manufacturing Company, R. W. Wagner and R. W. Goettler of Babcock \& Wilcox, and John Sawyer of Pall Corporation for providing filter specimens and for their helpful discussions.

\section{REFERENCES}

1. J. P. Singh, S. Majumdar, A. S. Wagh, T. Wenzel, and R. B. Poeppel, "Materials Qualification Technology for Ceramic Cross-Flow Filters," Argonne National Laboratory Report ANL/FE-91/1 (July 1991).

2. E. A. Ripperger and N. Davis, "Critical Stress in Circular Ring," Trans. Amer. Soc. Civ. Engr., Paper No. 2308, pp. 619-35 (1948).

3. J. P. Singh, D. Singh, and M. Sutaria, "Effects of Flaws on Fracture Behavior of Structural Ceramics," in this Proceedings.

4. M. G. Stout and J. J. Petrovic, "Multiaxial Loading Fracture of $\mathrm{Al}_{2} \mathrm{O}_{3}$ Tubes: $\mathrm{I}$, Experiments," J. Am. Ceram. Soc., 67[1] 14-18 (1984).

5. O. M. Jaddan, D. L. Shelleman, J. C. Conway, Jr., J. J. Mecholsky, Jr., and R. E. Tressler. "Prediction of the Strength of Ceramic Tubular Components: Part I-Analysis," J. Testing and Evaluation, 19 [3] 181-191 (1991). 